\title{
INFRASTRUCTURE CONCEPT FOR AUTOMATED AIRCRAFT AND AIR TRAFFIC OPERATIONS
}

\author{
Herman A. Rediess, Ph.D., Federal Aviation Administration', Washington, DC
}

\begin{abstract}
The infrastructure supporting our current air transportation system has evolved as a combination of separate systems interconnected to serve the needs of pilots and air traffic control (ATC). The human-centric approach to ATC with multiple levels of backup capability has proven very safe and has provided efficient service until the late 1990's when air traffic approached system capacity limits. As traffic demand increases there is concern that the number of aircraft operations may exceed the human's ability to directly control individual aircraft, even with sophisticated decision support tools. Various automation approaches to air traffic management (ATM) for handling more aircraft operations are being investigated at an algorithmic level. Assuming automation algorithms are developed that could handle significantly more traffic than human controllers, could they be implemented safely with the current infrastructure, which was designed for human operation and intervention? An infrastructure design approach is introduced for supporting fully automatic operations of aircraft and ATM. It is based on an integrated design of communication, space positioning and ATM functions using satellite, airborne and terrestrial elements. Such an infrastructure could support civil Uninhabited Air Vehicles (UAV) application and enable highly automated personal air vehicles.
\end{abstract}

\section{Background}

The infrastructure supporting our current air transportation system has evolved as a combination of separate systems interconnected to serve the needs of aircraft and air traffic control (ATC). The Global Positioning System (GPS), a separately developed system for the military, is being incorporated into the civil infrastructure. The FAA Operational Evolution Plan (OEP) [1], which

\footnotetext{
${ }^{1}$ On detail to NASA Aeronautics Research Mission Directorate
} as Director, University Programs focuses on increasing the system capacity, is upgrading elements of the ATC system, incorporating controller decision support tools, adding new runways and improving information sharing with airlines. The MITRE Center for Advanced Aviation System Development (CAASD) has estimated that the OEP improvements will provide the capacity needed for the next decade. As traffic demand continues to increase, there is concern that the number of aircraft operations may exceed the human's ability to directly control each individual aircraft, even with advanced decision support tools.

The primary purpose of ATC is safe aircraft separation. The current approach to safety is procedural, with surveillance and communications systems providing space positioning information to controllers and communicating to aircraft for traffic control information [2]. Navigation systems provide aircraft with space positioning and guidance information for following their flight plan; responding to ATC instructions; and, landing the aircraft. The current operational concept is basically for aircraft operators to be responsible for maintaining safe separation under visual flight rules (VFR) conditions and controllers to be responsible for aircraft separation under instrument flight rules (IFR) conditions.

In the early 1950 s to 1960 , Very High Frequency (VHF) Omnidirectional Range (VOR) sites were installed providing a network of line-ofsight navigation aids across the nation. Instrument flight routes were established along VOR vectors, because they were the primary navigation for aircraft. Since aircraft under ATC flew along those routes, ATC procedures were developed based on all aircraft flying along VOR defined straight-line segments and at planned air speeds and specified altitudes (procedural). This became important as traffic increased because it reduced the four dimensional (4-D) ATC problem for controllers to a

\section{U.S. Government work not protected by U.S. Copyright}


1-D problem (distance between aircraft along the route) most of the time, except when changing air speed or altitude at the controller's direction. However, it constrained aircraft to VOR straightline routes, essentially eliminating vast regions of the airspace under IFR conditions.

The relatively recent free-flight concept [3] allows freedom for aircraft to select the best flight route, not constrained to VOR routes, which potentially opens up the airspace. This concept was enabled by the increased accuracy of Inertial Navigation Systems (INS), GPS and Flight Management Systems (FMS) capable for highly accurate flight path control. ATC continues to provide surveillance and intervenes if there are any concerns about aircraft separation or requires positive control for balancing demand and capacity of sectors. Controllers still manage traffic and are responsible for safe separation in the terminal and airport areas.

System-wide safety of human-centric ATC is based on a series of backup operational modes for human control with less or degraded information. If surveillance radar information is lost, ATC can be performed with only voice communications by increasing aircraft separation and relying on wellknown procedures. If FMS, INS/GPS and the autopilot fail under IFR conditions, a pilot can fly manually with radio navigation aides. These procedures have proven safe, but can, and often do, limit system capacity.

To assist air traffic controllers to handle more traffic, decision support tools (DST) $[4,5]$ have been and continue to be developed and deployed. Although some reduction in delays have been observed using DSTs, adaptation of the tools to each FAA center continues to be challenging and projected benefits are not always achieved. Collaborative Decision Making (CDM) between Airline Operations Centers (AOC) and FAA National Command Center enabled sharing information about traffic status, routing plans, and certain actual operation information, has helped in reducing system delays. Additional research continues on concepts to increase system capacity, such as distributed [6] and airborne [7] separation assurance

ATC is much more complicated than described above, but that description is adequate to illustrate that the current human-centric design based infrastructure relies on dissimilar redundancy for the information required for aircraft operations and ATM, however, in general, each backup mode reduces system capacity to some degree.

Various automation approaches to air traffic management (ATM) for handling more aircraft operations have been investigated for FAA by MITRE as early as 1979, called "Automated EnRoute Air Traffic Control (AREA)" but reported at that time only in restricted distribution documents. The first public release document was in 1986 [8] and an advanced AREA concept published in 1992 [9]. Other automation concepts continue to be investigated at conceptual [10] and algorithmic levels $[11,12]$. Assuming automation algorithms are developed that could handle significantly more traffic than human controllers, could they be implemented safely with the current infrastructure, which was designed for human operation and intervention? If automated operations and ATM are required for the future air transportation system, an infrastructure would be needed that can assure no loss of critical functionality, even with multiple system element failures, and essentially no reduction of capacity.

Until substantial research is performed, including human- and hardware-in-the-loop simulation studies, it will not be known if fully automated ATM is possible or beneficial or just how far towards automated ATM is desirable. Such research probably will not be done for several years. Answers to those questions must be determined before committing to the future infrastructure, but it is appropriate to investigate infrastructures that could support full automation while automation and human roles are determined.

\section{Air Transportation in $\mathbf{2 0 2 5}$}

Conservative estimates of the air transportation system demand by 2025 is two and one-half to three times today's [13]. Those estimates are based on rational projections of current trends not taking into account potential new markets that might be stimulated by innovative new aircraft and systems with revolutionary capabilities enabled by new technology, operational concepts, procedures, policies, and infrastructure. Some examples illustrated in Figure 1 are personal air vehicles used 
for day-to-day transportation [14-16], revolutionary new transports [16], V/STOL [16] and airportindependent UAV cargo systems [17]. Demand for air transportation services could potentially increase by much more than three times today's, if such concepts stimulate strong consumer interest. In addition to increased capacity, the future air transportation must maintain its excellent safety record, provide the highest level of security and strive to improve our quality of life [18].

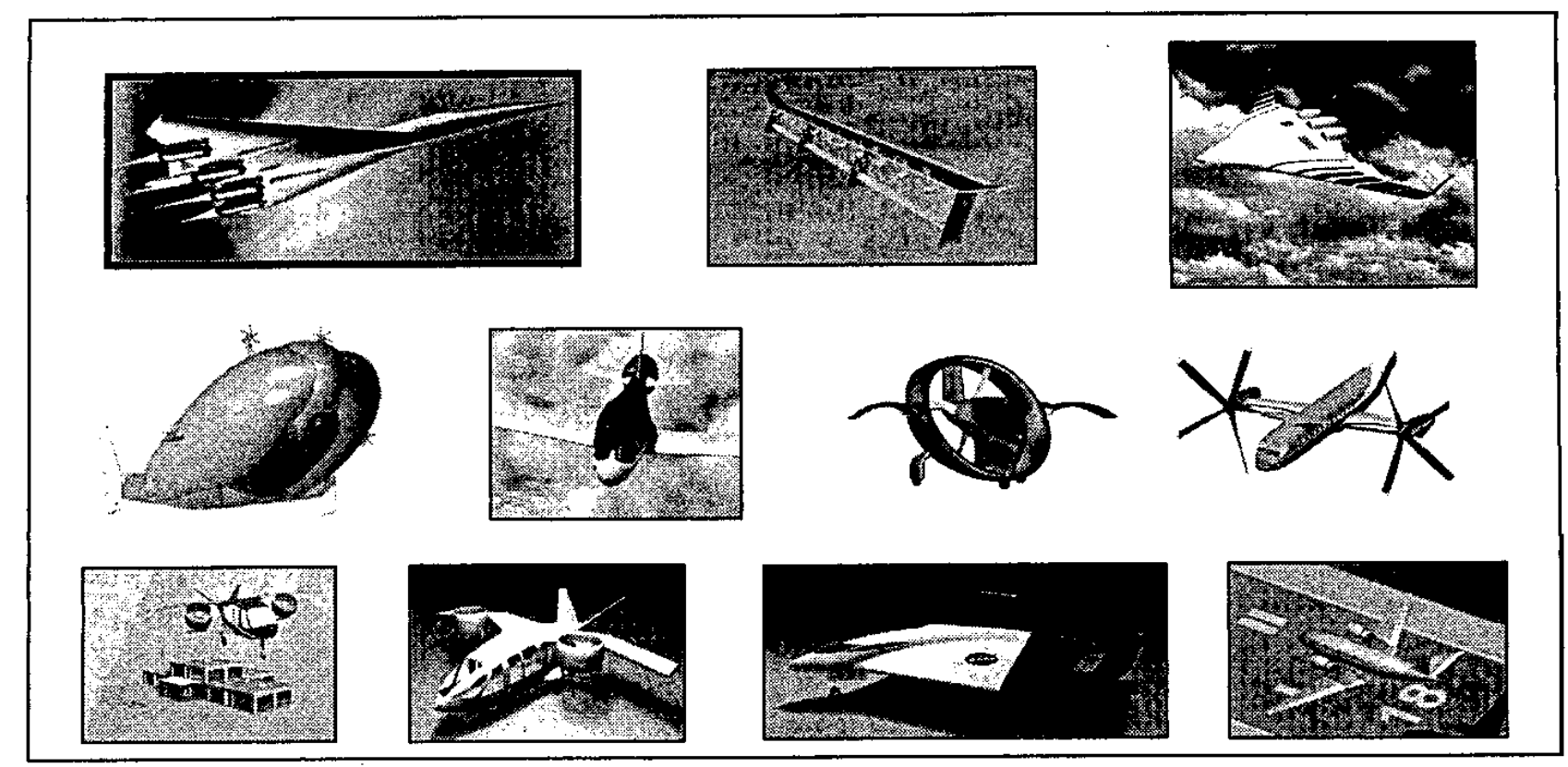

Figure 1. Possible Future Aircraft that the Infrastructure Should Be Prepared to Accommodate.

In a letter dated November 25, 2003 [13] from the Secretary of Transportation, Norm Mineta, to President Bush, recommending that the Administration launch a Next Generation Air Transportation System Initiative, the following goals were defined:

1. Reduce costs in the aviation system by at least $25 \%$ and expand industries supported by aviation, creating hundreds of thousands of new jobs

2. Provide three times the capacity of our current system, accommodating whatever level and type of future demand we may face while sustaining robust competition

3. Enable services that are tailored to individual consumer needs, making it possible to reduce the airport curb-tocurb transit time by $30 \%$ and the required time spent in the airports to less than 30 minutes. Consumers should expect arrivals and departures to be on-time $95 \%$ of the time.

4. Facilitate seamless air traffic management and security operations that improve our national and homeland defense without compromising access to aviation.

5. Maintain aviation's record of the safest mode of transportation, while becoming one of the quietest and most fuelefficient modes.

6. Retain our role as the world leader in aviation through strong U.S. leadership in transforming the world's aviation system.

Stimulating economic growth and improving quality of life are other desirable goals for future air transportation. The availability of efficient transportation and air transportation in particular has been a critical factor in stimulating economic growth. Even in the e-commerce era, goods 
ordered over the internet must be delivered to the consumer, and are most often delivered by air. The future air transportation system should strive to be unconstrained in capacity and at an affordable price to support what ever demand our economy "wants" it to support.

Air transportation itself has become intrinsic with the quality of life we have come to enjoy. Over the past three decades, personal air travel has become more affordable for an increasing portion of the U.S. population. People are retiring earlier and living longer. As the 77 million baby-boomers start retiring in a couple years, the number of retired people wanting air travel for leisure and family activities will dramatically increase. The future system we plan should stimulate that market, not constrain it.

Safety must include all aspects of air transportation, including all aircraft types from transports to military, general aviation, business aircraft, and recreational aircraft, UAVs, and space transportation vehicles. It must cover all types of operations, including subsonic and supersonic flight, recreational, and special civil operations, like fire fighting, remote area helicopter operations, crop dusting, law enforcement, medical emergencies and space transportation operations in the civil airspace. It must include all safety critical aircraft and infrastructure systems, procedures and policies involved in ATM.

Security must be design into the future air transportation system to achieve the high level of security and minimize the disruption of people and goods flowing through the system. Our goal should be no disruption of the flow of passengers or cargo and minimum restrictions of aircraft operations while assuring security.

Protecting our environment is extremely important to maintaining and improving quality of life. Reducing the impact of aviation on the environment and the use of facile fuel have to be major requirements of the future transportation system.

UAVs are here to stay. They are operational for military missions and a limited number of civil applications are on the drawing board. ACCESS 5 is an industry-government program to enable safe operations of UAVs within the NAS within 5 years.
The initial objectives are modest, accepting "special-use-airspace-type" operations from airports for climb-out and descent and autonomous flight above 18,000 feet altitude. They are expected to follow existing ATC procedures with controller communications to a remote pilot, who serves as a backup. The future air transportation system should be able to accommodate autonomous UAVs operations with no more safety or security restrictions than for manned aircraft. That implies some form of automatic ATM. Why should UAVs be limited to take off and landing at airports where the greatest congestion already exists? Why not provide an infrastructure that could support operations from any convenient location for the operator, such as from rooftops, industrial parks [17], etc.? With this flexibility and freedom of operation, UAVs may come to outnumber piloted aircraft. What infrastructure might be needed to support hundreds of thousands of UAVs safely?

Flexibility and freedom of the personal automobile is an important aspect of U.S. culture and quality of life, yet the personal air vehicle for transportation has not developed in any significant way. The future air transportation system should not only allow for such aircraft, but should provide, at least, an infrastructure that enables such operations in an affordable manner. Some have suggested [16] that a Vertical Take-Off and Landing (VTOL) "converticar" might be possible in the near future at a retail price of around $\$ 50,000$ if produced in large quantities. It is technically feasible to develop personal aircraft that essentially flies itself, with the operator merely designating the destination and desired route. Such an aircraft could be easier to operate and require no more skill or training then to operate an automobile.

If the infrastructure could support millions of personal aircraft operating with the type of flexibility and freedom we enjoy with cars and do it safely, industry is likely to develop that market. As an adequate market develops, automobile-type mass production might follow, driving the price down to the point where an ever-increasing segment of the population could afford them.

\section{Concept of Operation}

A hypothetical concept of operation is suggested here for the desired future air 
transportation system, assuming the infrastructure and aircraft systems can support it. It is substantially different from that developed by RTCA in 2002 [19]. The following concept of operation has not been validated; some aspects are inconsistent with current aviation policy; and, some aspects are counter to stated professional associations' positions. However, it is necessary to define a concept of operation consistent with automated operations in order to define a supportive infrastructure. It also serves to illustrate the type of revolutionary concepts that the research community should investigate at this early stage of research for a 2025 and beyond system.

\section{National Airspace System (NAS) Management}

All NAS is controlled airspace, except for certain areas reserved for recreational flying. Aircraft operating in controlled airspace are required to have transponders and data links that can not be tumed off, and are expected to have minimum avionics capable of supporting fully automatic flight operations. Preferential treatment is given to those with equipage that enhances system capacity. Piloted aircraft without the minimum equipage for automatic operations will only be accommodated at lower priority on a "space and time available" basis. Airspace reserved for recreational flying under FVR conditions has no minimum avionics requirements (see Recreational Aircraft section). All UAVs must have the minimum automation equipage (see UAVs section). All aircraft must have emergency locator transmitters with satellite positioning equipment to aid in search and rescue.

ATM is highly automated with human oversight and management of traffic flow and system capacity. Primary separation assurance is the responsibility of the aircraft operator, assisted by automation. Automated conflict detections and resolution is performed on board aircraft and independently in ground-based ATM systems. The ATM system allows the aircraft operators to select and automatically fly their preferred flight path when safe, subject to possible flow management direction. Equipped aircraft are expected to use flight management systems (FMS) to automatically fly 4-D trajectories, which are transmitted and updated to the responsible regional center ${ }^{2}$.
Ground-based intervention for potential conflict resolution by air traffic managers is an emergency backup capability and expected to be used rarely.

Air traffic managers located at regional centers ${ }^{2}$, use voice and data link communications to assist aircraft without the minimum automation equipage for air traffic control. The automated ATM system will interface directly with the aircraft via data link. It will provide air traffic control information, including flight path changes, spacing conflict detection and resolution. The air traffic manager monitors this function and may have to enter estimated 4-D trajectory information if not available from the data link. They can communicate with the pilot by voice if necessary. Since the data from these aircraft may be less reliable, the ATM systems must provide wider separation and treats them at lower priority than aircraft with automation equipage for safety and traffic flow efficiency.

Recreational flying areas are not controlled by an ATM system, but are self managed by the users.

Traffic Flow Management (TFM) and system-wide capacity management within the NAS is ground-based through one national center interconnected with several regional centers. Strategic TFM is performed at the national center. TFM is monitored at the regions and modified, if necessary for tactical reasons. For example, rapidly changing weather at one region may require a local TFM change. The proposed modification would be coordinated with the national and adjacent centers. Flight planning for user-preferred routing is negotiated automatically between the aircraft operator and the TFM system, which balanced user preference with system-wide efficiency/capacity and assures conflict-free routes. System-wide efficiency and capacity takes preference over individual operator efficiency. TFM directed changes are implemented through the automated ATM system.

\section{Global Airspace System (GAS) Management}

GAS centers located in North America, Europe and Asia for the northern hemisphere and South

\footnotetext{
${ }^{2}$ Regional Center is used rather than Sector to avoid confusion with current operations.
} 
America, Africa and Australia for the southern hemisphere, manage international traffic. The GAS centers coordinate with national centers involved with specific international flights for flight planning and strategic TFM. A common minimum avionics suite is required to fly internationally.

\section{Aircraft Operations}

\section{Commercial Air Transports, Business} Aircraft and Air Taxis for passengers operate with one or two pilots, depending on the equipage. Transports with only one pilot are required to fly 4$D$ trajectories using automatic FMS data-linked directly to the ATM system. The pilot monitors the automated FMS and other systems. Passenger aircraft not equipped for fully automatic operations must have two pilots and fly 4-D trajectories, which may be entered manually into the FMS by the pilots. The trajectories must be data-linked and updated periodically to the ATM system. Air Taxis appropriately equipped generally operate with one pilot in the same manner as commercial transports.

Cargo Transports operate with one, two or no pilots, depending on the equipage. Aircraft with one or two pilots operate the same as for passenger transports. UAV cargo transports operate as indicated in the UAV section.

V/STOL Aircraft operate with one, two or no pilot (see UAV section), depending on the mission and equipage. V/STOL aircraft can negotiate userpreferred flight plans that take full advantage of the unique performance capabilities, subject to safety, security, and system-wide efficiency and capacity considerations. They are required to fly 4-D trajectories, which are provided to the ATM system via data link. V/STOL aircraft equipped for fully automated operations can operate to and from any designated landing area under VFR and IFR category III conditions. For authorized emergency aircraft, this includes any area with sufficient unobstructed space to operate safely, such as parking lots and streets, as they do now under VFR conditions.

\section{Uninhabited Air Vehicles (UAV) may} operate in controlled airspace if equipped for fully automatic operations and some form of backup remotely-piloted capability. Normal operation is the same as for automated piloted aircraft, from flight planning to all flight phases. In most cases the UAV operations center can serve as the remotelypiloted emergency backup. Once operational reliability is demonstrated, one remote pilot can generally monitor and backup as many as five to seven UAVs within the data link range.

Personal Air Vehicles (PAV) operate with one or no pilot, depending on the equipage. Aircraft not equipped for fully automated operations require a fully qualified pilot and appropriate avionics for piloted flight. Licensed nonpilots may operate PAVs equipped for autonomous flight and "safety-net" capability. Such aircraft have the same autonomous capabilities of UAVs and the operator simply designates the destination, preferred routes and engages the automatic system, which flies the aircraft. The safety-net is an emergency system which automatically lands the PAV in the closest designated landing area in case of engine failure. PAVs with V/STOL capabilities may operate as discussed in that section.

Recreational Aircraft include most gliders, ultra-lights, hang-gliders, home-built and experimental aircraft used only for recreation. They are generally restricted to designated recreational airspace unless equipped to fly in controlled airspace. Non-equipped aircraft can only fly in controlled airspace in transit to another recreational airspace with the approval and assistance of the air traffic manager for the region(s).

\section{Terminal Area and Surface Operations}

Terminal areas are of three types:

1. metropolitan areas with one or more major airports, typically several small airports, many minimally equipped landing sites, and an unlimited number of landing areas for emergency V/STOL aircraft;

2. towns with small airports, many minimally equipped landing sites, and an unlimited number of landing areas for emergency V/STOL aircraft; and,

3. areas with no airports but many minimally equipped landing sites, and an unlimited number of landing areas for emergency V/STOL aircraft. 
All airports and landing sites/areas will have infrastructure to support automatic landing and take-off. If roadable air vehicles (RAV) become a reality, the "unlimited" landing areas would expand to include almost any road not restricted for security reasons.

Traffic in terminal areas is generally managed by automated ATM systems, including sequencing in and out of landing areas. In areas where traffic is sufficiently light, air traffic may self organize with the ATM system monitoring and advising on potential conflicts, but prepared to take control if necessary.

\section{Surveillance and Security}

Surveillance has a different role in this future of highly automated system. Since the concept of operation is for fully automated operations and the systems are designed to operate with no human intervention, at least under most situations, surveillance has two primary purposes: 1) security, the most important; and, 2) aircraft operations planning. In areas where fully automated operations are not warranted, surveillance is still used to determine the need for human intervention.

Security must be fully integrated into the air transportation system. Only the surveillance aspects of security are discussed here. Surveillance must track and positively identify all aircraft large enough to be a threat to security. This information must be provided to the responsible military response organization in real time. It should also be able to detect unusual aircraft behavior that could indicate a possible threat.

\section{Infrastructure Desired Capabilities}

The research community should investigate infrastructures that could support, even stimulate, the most optimistic desired futures then define an infrastructure that is robust, adaptable and scaleable from the minimum to the most optimistic futures. The actual infrastructure would evolve only to the degree actually needed at any point in time.

The future infrastructure should be capable of supporting fully-automatic aircraft operations from taxiing, takeoff, the entire flight path, landing, and ground operations under VFR and IFR conditions.
It should be capable of supporting IFR operations from all airports, heliports and virtually any desired location, such as emergency medical evacuation helicopters operating from any street to a hospital, or autonomous cargo UAVs operating in and out of industrial parks, or automated personal air vehicles operating from any street. It should support automated ATM to varying degrees for national and international needs. In the most affluent states it should be capable of handling millions of autonomous aircraft. It should be capable of fullyautomated airport and heliport operations under VFR and IFR conditions. It should support adaptive, programmable runways, taxiways and gates, automated ground traffic management and aircraft servicing.

The infrastructure should support non-intrusive and seamless aviation security for all aircraft, passengers, luggage and cargo from all origins, including remote check-in. It should provide fulltime surveillance and positive ID of all aircraft. Passenger, luggage and cargo processing should be automated and seamless across transportation modes. Luggage might even take different a route than the passenger.

The infrastructure should provide ubiquitous in-flight information services for business and entertainment at all times throughout the flight. It should support efficient, convenient and seamless inter-modal transportation with multiple options for door-to-door travel.

All functionality of the infrastructure must be robust. The system should be flexible, adaptable to change and tolerant to human and system errors. It must have sufficient reliability and availability to essentially never lose safety-critical functionality and, if possible, should enable relatively low-cost aircraft equipage. "Safety-critical functionality" means any function, such as precise aircraft location, velocity and orientation relative to the ground or another aircraft that is critical to controlling an aircraft or managing air traffic safely. Loss of that function puts at risk the aircraft and/or human life.

\section{Operational Factors}

Operation capabilities should be available to all users 24 hours a day, seven days a week and 356 
days a year. Full service should be available essentially everywhere desired but scaleable to local needs determined by local authorities. The infrastructure should support global interoperability. Aircraft should require only one set of avionics to operate in any country, consistent with the desired level of service. If possible, the minimum suite of avionics required should be affordable to anyone who wants to fly and owns an aircraft, including fractional ownership.

\section{Architecture Characteristics}

NAS features needed to support the Automated Airspace Concept (AAC) [11] have been analyzed [20] to estimate the safety of the concept and concluded that with appropriate redundancy it could be at least as safe as the current system. However, the AAC was designed to operate with air traffic controllers to reduce their workload and increase system capacity. It automates routine separation monitoring and traffic control allowing the controllers to devote more time to strategic problem solving, traffic flow management, and handling unusual events. Because of the high level of autonomous control authority delegated to the ground-based elements of the AAC, it was essential to design the system to ensure operational integrity after failure of critical software or hardware in the ground-based elements. Controllers would still assume separations assurance responsibilities if there is a data link or other critical on-board system failure. The AAC is a major step towards fully automated en route ATM and would be a candidate for transition to full automation.

This paper does not present a final design and analysis of an architecture for an infrastructure to support fully automated operations, but suggests certain important characteristics of the communications, space positioning, ATM information processing/procedures and avionics, that should be researched.

Communication systems are needed to support multiple requirements with different levels of criticality, which are best served by independent networks. The following guidelines are from the technical viewpoint. Other factors important to implementation, such as cost effectiveness of the service and company proprietary information which may place additional requirements on the design, are not addressed here.

System-wide safety-critical information, such as aircraft space positioning information for precise guidance and ATM separation information, must be highly reliable and requires multiple redundancy. This would also apply to aircraft-to-aircraft datalinks used for close proximity operations and separation assurance. Sever weather information that could effect safety should be included in this network. Safety can be improved by providing safety-critical functionality from multiple dissimilar sources.

Information needed for mission-critical but not safety-critical functions should be provided over a second independent network. This would include such items as flight path navigation, non-flightcritical weather information, and airline operation center $(A O C)$ mission information. This information network might be duplex or simplex with an alternative backup source. Information for enhancing system capacity, but is neither flight safety nor mission critical, could be provided over a separate simplex network. This would include collaborative decision making (CDM) information shared among AOCs, aircraft operators and ATM centers. Business and entertainment information should be provided over a fourth network, possibly a commercial network available to aircraft. The aircraft industry would have to assure that this network doesn't interfere with flight-critical avionics.

Space positioning information used for precise guidance, landing and separation assurance is flight critical and must be extremely reliable. GPS is becoming a standard for the U.S. and Europe is developing Galileo as their primary space positioning system for aviation. UAVs currently use GPS for autonomous operations for military missions and a few civil applications. However, a single source for safety-critical functions supporting very large numbers of automated aircraft in civil airspace, as discussed above, would probably not provide adequate safety. Multiple independent system using satellites, terrestrial and airborne sensors/systems should be considered. For example, space positioning information could be provided in aircraft from satellite-based, groundbased, and inertial systems, radar altimeters and 
data-linked optimal estimations fused from multiple sensors at an automated ATM center. Relative space position between two or more aircraft might be augmented by aircraft-to-aircraft distance measuring systems and/or data-links for separation assurance in terminal areas and ground operations. An integrated design approach for multi-fail operational capability with no loss of functionality should be used for the space positioning information system, which is discussed in the next section.

Surveillance for aircraft operations planning could be from a dependent source, e.g., extracted from the mission-critical network navigation information. Surveillance for security should include an independent system capable of tracking and identifying all, including non-cooperative, aircraft large enough to be a threat. Although not safety-critical, security surveillance systems must have very high availability and be protected form sabotage.

\section{ATM information, processing and} procedures in a fully automated ATM system becomes safety-critical. The architectural characteristics for these elements are highly dependent on the operational concept and airspace management approach defined to enable automated ATM. The operational concept must cover all types and categories of aircraft and modes of operation, from UAV cargo aircraft and automated personal aircraft to very large passenger airliners and space transportation vehicles operating in civil airspace. Dynamic airspace management might be considered to segregate UAVs from human operated and passenger aircraft.

Duplicating aircraft separation assurance and portions of the ATM functions in ground-based systems and on the aircraft should be considered, in case one side or the other is disrupted or the airground data link is disrupted. The automated ATM processing software should also be redundant and dissimilar. For example, Erzberger's Automated Airspace Concept (AAC) [11] proposes a backup safety aircraft separation system called Tactical Separation Assured Flight Environment (TSAFE). It backs up the Automated Trajectory Server (ATS) software proposed to be installed in the FAA En Route Automation Modernization (ERAM) groundbased host computer system. TSAFE would be a set of algorithms independent from ATS devoted exclusively to preventing loss of separation for short-term predicted conflicts.

The safety-critical information needed for automated ATM should come from the safetycritical communications network or networks. The sensing and processing systems are safety-critical and must provide full service functionality under all but extremely rare circumstances. Since it is possible that some elements of the system will fail periodically it must be designed with multi-fail operational capability, probably using dissimilar redundancy.

Avionics for aircraft operating in controlled airspace will contain several safety-critical elements. Flight control systems for autonomous operations must support fully automatic flight from take-off to automatic landing and ground operations. Flight management systems provide automatic operations from brake release to take-off through landing and taxiing to a parking location. These systems should have multi-fail operational capability.

All aircraft in controlled airspace must have automated conflict detection and resolution and automated traffic alert and collision avoidance system (TCAS), which are independent of the ground-based automated ATM system.

\section{Integrated System Design}

An integrated design approach is suggested for the safety-critical infrastructure, including space positioning, communications, and ATM processing systems. The basic approach is described by Robert Schwab, et.al. [21], however they address conventional CNS/ATM concepts and not fully automated operations. Integrated design does not mean that all systems will be integrated into one single system. In fact, use of independent dissimilar redundancy should be one of the design options. It means that the total system requirements and all assets potentially available to support those requirements are considered in design alternatives. A driving requirement is for full functional availability in all but extremely rare situations even with multiple failures, which means multi-fail operational reliability. 
The first step in the process illustrated in Figure 2 is to develop a mission model for the time frame to be serviced by the infrastructure. The mission model is a detailed description of 2025 air transportation, discussed earlier, including estimates of traffic demand for each type of aircraft. A systems analysis of the mission is performed to evaluate high-level safety, capacity, efficiency, security, and other objectives of the user communities. The design process analyzes the concept of operation, system requirements and design alternatives and performs trade studies to define a feasible safety-critical infrastructure architecture. Central to the analysis are the automation technology and human role. The trade studies include considering various levels of automation and roles of human participation. An initial concept of operation to meet the mission goals was discussed earlier. This is an iterative process until one or more infrastructures have been defined that satisfy the mission goals.

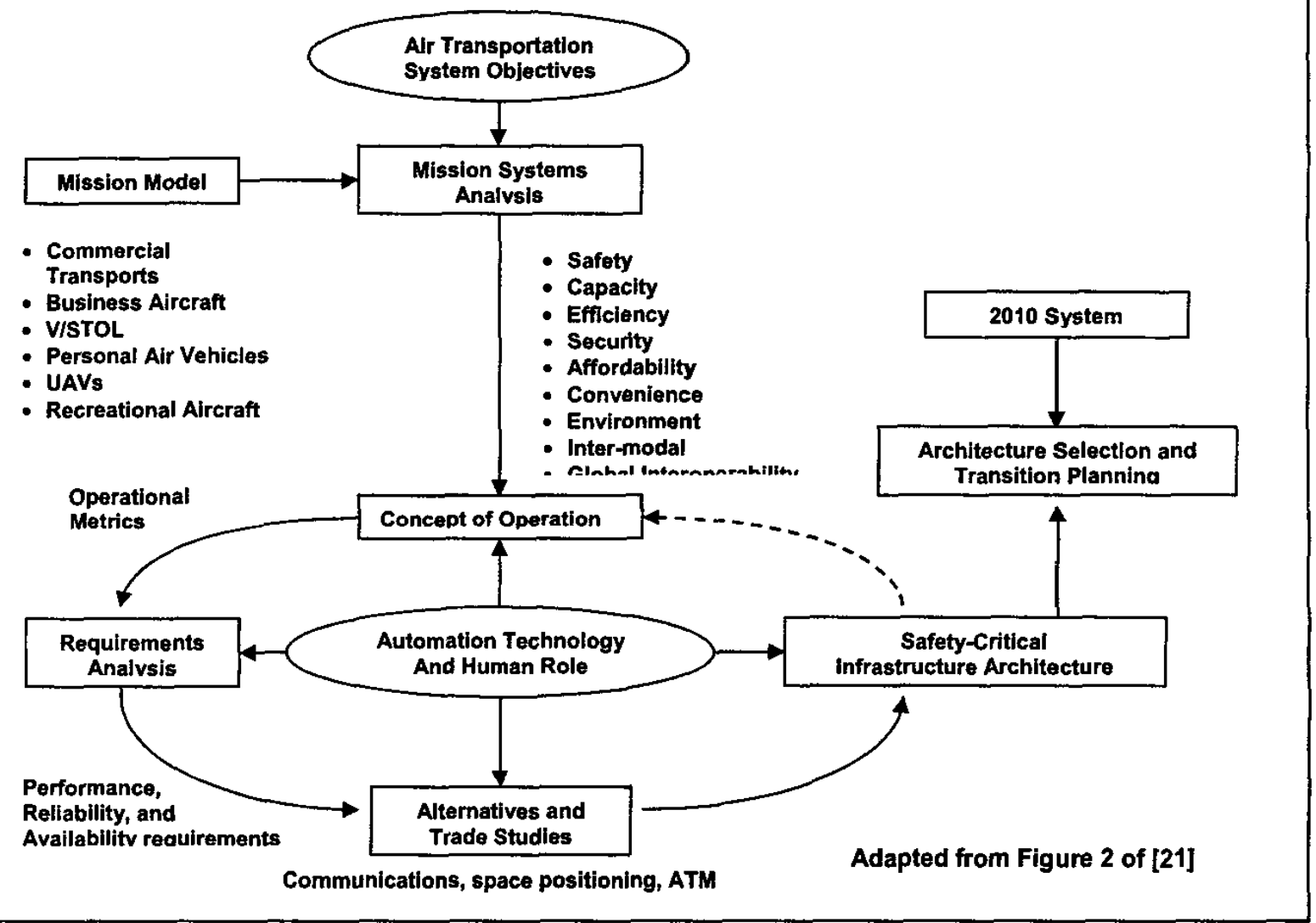

Figure 2. Systems Analysis and Design Process for Safety-Critical Infrastructure

The design philosophy suggested for considering alternatives for the safety-critical infrastructure is similar to that for aircraft fly-bywire flight control systems $[22,23]$. Consider all space, terrestrial, and aircraft existing and potential future assets. Robert Crow [24] presents a concept for an integrated ground and satellite-based system concept for global CNS/ATM, including Category
III landing guidance, but for the current humancentric system. His rationale for integrating ground-based space positioning information with GPS is primarily to protect against jamming of the GPS, but is in the direction suggested here.

The integrated "fly-by-wire" design approach for space positioning information considers 
satellite, terrestrial, and aircraft on-board sensors and determines the redundancy and redundancy management necessary to meet the functional reliability requirements. Airborne radar altimeters are considered as another sensor for the integrated design, particularly at low altitudes. Aircraft-toaircraft data links and distance measuring sensors are considered for separation assurance and automatic station keeping in formation takeoff and landing.

Don't limit design options to known existing system capabilities. For example, if new capabilities are needed for GPS, Galileo and/or new space-based and ground-based augmentation system, they can be proposed for future system upgrades. Long-range and terminal area radars currently used for air traffic controller information should be reconsidered for how they could support automated ATM. Although less accurate than GPS, radar represent an independent source for space position and if integrated properly with GPS and aircraft initial sensor information can increase the reliability and availability of the space position information. For example, integrating groundbased radar data with an INS/GPS sensor system, although not as accurate as GPS, could provide incremental drift compensation if GPS data are lost.

Once candidate infrastructures for 2025 are defined by this process they must be evaluated with respect to transitioning from the baseline system expected to be in place by 2010 . Transition from the 2010 infrastructure, which must be viable in all dimensions, i.e., technical, financial, and political, is the final factor in selecting the architecture.

\section{Concluding Comments}

The primary motivation for this paper is twofold: to encourage research that supports the most optimistic possible future air transportation system that could stimulate new markets and a higher quality of life; and to motivate systems studies for highly reliable safety-critical infrastructures that may be needed to support fully automated aircraft and air traffic operations.

An optimistic air transportation system for 2025 and beyond was defined that embraced revolutionary new aircraft and aircraft operations. A hypothetical concept of operation for a highly automated air transportation system was described. A set of desired infrastructure capabilities and safety-critical infrastructure architecture were identified. Finally an integrated system design approach was suggested.

\section{Disclaimer}

The views presented in this paper are strictly those of the author and do not represent an official position of FAA or NASA.

\section{References}

[1] Anon. June 5, 2001, "Operational Evolution Plan, Version 3.0", transmitted by letter to Members of the Aviation Community from Jane Garvey, Administrator, FAA: annual updates at http://www.faa.gov/programs/oep.

[2] Nolan, Michael S., 1994, "Fundamentals of Air Traffic Control", Second Edition, Wadsworth Publishing Company.

[3] Anon. 1995, "Final Report of the RTCA Task Force 3: Free Flight Implementation", Washington, DC, RTCA.

[4] Erzberger, Heinz and William Nedell, December 1988, "Design of Automation Tools for management of Decent Traffic", NASA-TM101078, December 1988.

[5] Erzberger, Heinz, June 1989, "Design of Automated System for Management of Arrival Traffic", NASA-TM-102201

[6] Krozel, Jimmy, Mark Peters, Karl D, Bilimoria, Changkil Lee, and Joseph S. B. Mitchell, December 3-7, 2001, "System Performance Charcteristics of Centralized and Decentralized Air Traffic Separation Strategies", Proceedings of the $4^{\text {th }}$ USA/Europe Air Traffic Management R\&D Seminar, Santa Fe, NM,

[7] Bilimoria, K. D., K. S. Sheth, H. Q. Lee, and S. R. Grabbe, August 14-17, 2000, "Performance Evaluation of Airborne Separation Assurance for Free Flight", AIAA paper 2000-4269, Guidance, Navigation, and Control Conference, Denver, CO.

[8] Kingsbury, James A., October, 1986, “Air Traffic Control Automation: An AREA for This Century", MITRE MP 86W00028. 
[9] Kingsbury, James A. and Gary L. Klein, January 1992, "Advanced AREA Capabilities: A High Level Description”, MITRE MTR-91W00158.

[10] Le Tallec, Cl. and Daniel Delahaye, July 1417, 2003, "Air Transportation System for 2020 2030, A Research Viewpoint" AIAA 2003-2670., AIAA/ICAS International Air and Space Symposium and Exposition: The Next 100 Years" Dayton, $\mathrm{OH}$.

[11] Erzberger, Heinz, December 3-7, 2001, "The Automated Airspace Concept", Proceedings of the $4^{\text {th }}$ USA/Europe Air Traffic Management R\&D Seminar, Santa Fe, NM.

[12] Erzberger, Heinz, August 29 - September 3, 2004, "Transforming the NAS: The Next Generation Air Traffic Control System". To be presented at the $24^{\text {th }}$ International Congress of the Aeronautical Sciences, Yokohama, Japan.

[13] Mineta, Senator Norm, November 25, 2003, "America at the Forefront of Aviation: Enhancing Economic Growth" attachment to Secretary Mineta's letter to the President of the United States.

[14] Moore, Mark D., 2003, "Personal Air Vehicles: A Rural/Regional and Intra-Urban OnDemand Transportation System", AIAA paper 2003-2646.

[15] DeLaurentis, Daniel, Taewoo Kang, Choongiap Lim, Dimitri Mavris, and Daniel Schrage, 2003, "System-of-Systems Modeling for Personal Air Vehicles", AIAA paper 2003-

[16] Bushnell, Dennis M., August 19-21, 2003, "On (Civil) Aviation Future(s)", white paper at NASA Langley Research Center Aeronautics Futures Workshop, Williamsburg, VA

[17] Rediess, Herman A., July 14-18, 2003, "Airport-Independent Uninhabited Air Vehicle
Cargo System Concept", presented at the AIAA/ICAS International Air and Space Symposium, Dayton, OH. AIAA 2003-2502

[18] Walker, The Honorable Robert S, and Commissioners, November 2002, "Final Report of the Commission in the Future of the United States Aerospace Industry", Arlington, VA, www.ita.doc.gov/aerospace/aerospacecommission.

[19] Anon. 2002, "National Airspace System Concept of Operation and Vision for the Future of Aviation". Washington, DC, RTCA, available on the web at http//:www.rtca.org.

[20] Andrews, John W., June 2004, "Safety Assessment Model for the Automated Airspace Concept", 42PM-AATT-0018, MIT Lincoln Laboratory.

[21] Schwab, Robert W., Aslaug Haraldsdottir, and Anthony W. Warren, September 28-30, 1998, "A Requirements-Based CNS/ATM Architecture", 1998 World Aviation Conference, Anaheim, CA, paper 985552.

[22] Osder, Steve S. Mar-Apr 1983, "Generic Faults and Architecture Design Considerations in Flight Critical Systems", AIAA Journal of Guidance and Control, Vol. 6, No. 2.

[23] Osder, Steve S., October 17-20, 1988, "Digital Fly-by-Wire Systems for Advanced AH-64 Helicopters", $8^{\text {th }}$ Digital Avionics Conference, AIAA paper 88-3922.

[24] Crow, Robert P., April 15-18, 2002, "Civil Aviation's Next Generation Global NCS/ATM System", AirNav, Inc. Report, and paper presented at the IEEE PLANS Conference, Palm Springs, CA. 